\title{
PATRYSTYKA W CZASOPISMACH 1999 ROKU
}

1. ACTA PHILOSOPHICA 8 (1999) nr 1-2:

D.M. Searby - Faith, the criterion of knowledge: Remarks on a definition attributed to Aristotele by Clement of Alexandria 333-345.

2. ACTA UNIVERSITATIS NICOLAI COPERNICI (1999) nr 31 (Historia): M. Szarmach - O dwu listach (LVII $i$ LXX) św. Hieronima 151-156; P. Nehring - „Exordium” w tacińskich żywotach swiętych z IV $i \mathrm{~V}$ wieku 179-199.

3. ACTA UNIVERSITATIS WRATISLAVIENSIS (1999) nr 36 (Filozofia): J. Zieliński - Alegoreza jako metoda filozoficzno-egzegetyczna $w$ ujęciu Orygenesa 295-320; M. Bakalarz - Transcendencja bytu Bożego według Pseudo-Dionizego Areopagity 321-334.

4. AEVUM 73 (1999) nr 1-3:

L. Cotta Ramosino - II supplizio della croce in Silio Italico: Pun. I 169-181 e VI 539-544, 93-105; I. Ramelli - Edessa e i Romani fra Augusto e i Severi: aspetti del regno di Abgar V e di Abgar IX, 107-145; T. Lorini-Una versione

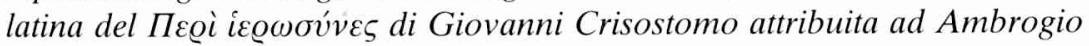
Traversari 549-570; G. Silagi - Ludwik Traube und der münchener Lehrstuhl für Patristik (mit einem Exkurs zur Thesaurus - Frage) 837-890.

5. THE AMERICAN BENEDICTINE REVIEW 50 (1999) nr 1-4:

C. Stewart - Feature Review: Three recent Studies on ancient Monasticism 3-11; T.G. Kardong - Clarifications of Benedict's Chapter on Humility: A Reply to Francis Seeburger's Article „Humility, Maturity and the Fear of God" 12-29; N. Groves - Rule and Life: A Study in the Interpretation and Living of the Rule of St. Benedict and the Buddhist Vinaya Pitaka 30-63; A. Nugent - Benedict: A sense of Prayer 149-160; G. Penco - Conditions and Currents in Sixth-Century Italian Monasticism 161-179; D.W. Fagerberg - Time in the Desert Fathers 180-202; H. Feiss - Water, Oneness and the West: Benedictine Theological Reflections 239-252; B. Studer - „Schola Christi" in the Rule of St. Benedict 327-345; D.N. Bell - Christ in the Desert 381-396; J.W. Houghton - St. Bede among the Controversialists: A Survey 
397-422; P. Caveglia - Your Way of Acting Should be Different (4. 20): Catholic Social Teaching and the Rule of Benedict 423-436; B. Guevin A New Gregorian Controversy. The Authorship of the Commentary on First Kings in Doubt 437-443.

6. AMERICAN CATHOLIC PHILOSOPHICAL QUARTERLY 73 (1999) nr 1-3:

A.A. Panny-White - Does Augustine Contradict Himself in "Contra duas epistulas Pelagianorum» 407-418.

7. ANALECTA CRACOVIENSIA 30-31 (1998-1999):

S. Stabryła - The concept of martyrdom in Prudentius" "Peristephanon» 561-569.

8. ANÁ MNESIS 9 (1999) nr 1-2:

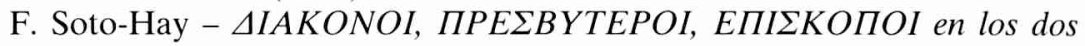
primeros siglos de la historia de la Iglesia 5-32.

9. ANAMNESIS 5 (1998/99) $\mathrm{nr}$ 1-4 + Nr specjalny:

(Nr specjalny) S. Czerwik - Św. Ambroży: mistagog starożytnego Kościoła - o misterium i mistagogii 25-41; F. Drączkowski - Kerygmat pisemny w nauce Ojców Kościoła 42-54.

10. ANCIENT PHILOSOPHY 19 (1999) 1-2 + Nr specjalny:

T. M. Popa - Functions of the Typos Imagery in Philo of Alexandria 1-11.

11. ANGELICUM 76 (1999) nr 1-4:

W. Dąbrowski - La cristologia nel «Super Boetium De Trinitate» di San Tommaso d'Aquino 161-182.

12. ANNALES 54 (1999) $\mathrm{nr} 1-6$ :

É. Rebillard - Église et sépulture dans l'Antiquité tardive (Occident latin, $3^{e}$ - $6^{e}$ siècles) 1027-1046; M. Lauwers - Le cimetière dans le Moyen Âge latin. Lieu sacré, saint et religieux 1047-1072.

13. ANNALI DI STORIA DELL' ESEGESI 16 (1999) nr 1-2:

A. Magris - L' escatologia valentiniana 133-139; G. Iacopino-Alcuni aspetti dell' escatologia gnostica nei testi non valentiniani 141-159; M. Rizzi L'escatologia degli apologisti: giudizio, rivelazione e teodicea nella seconda metà del II secolo 161-178; A. D'Anna - Escatologia e Scrittura in Ippolito. Speculazioni cronologiche, antiromanismo, antigiudaismo 179-196; J.J. Ayan Calvo - Escatología cósmica y Sagrada Escritura en Ireneo de Lyon 197-233; G. Lusini - Escatologia e Scrittura nelle più antiche tradizioni 235240; S. Tampellini - Aspetti di polemica antigiudaica nell'opera di Esichio di Gerusalemme (con particolare attenzione al "Commentario al Levitico") 353-358; M. Pesce - Cassiodoro e gli ebrei: provvedimenti politici e riflessione teologica. Dalle «Variae» al «Commento ai Salmi» 379-401; G. RaspantiAspetti formali dell'esegesi paolina dell'Ambrosiaster 507-536.

14. ANNUARIUM HISTORIAE CONCILIORUM 31 (1999) nr 1-2:

S. Wessel - Nestorius, Mary and Controversy in Cyril of Alexandria's 
Homily IV («De Maria deipara in Nestorium», CPG 5248), 1-49; H.J. Sieben - Die Mosaikinschriften der Bethlehemer Geburtskirche vor dem Hintergrund der byzantinischen Tradition der Konzilssynopsen 255-296.

15. ANTIQUITAS 24 (1999):

T. Kotula - „Numidia, ubi vos praepolletis”: kilka uwag o chronologii schytku starożytności i o donatystach 11-17; W. Suder - Źródta epigraficzne w badaniach demograficznych Imperium Rzymskiego: uniwersalność 57-73; A. Wypustek - Oskarżenie chrześcijan o magię erotyczną: uwagi na temat zapoznanego aspektu prześladowania chrześcijan w starożytności 81-99.

16. ARABIC SCIENCES AND PHILOSOPHY 73 (1999) nr 1-2:

S.P. Brock - Two Letters of the Patriarch Timoty from the Late Eighth Century on Translations from Greek 233-246.

17. ARCHIV FÜR RELIGIONSGESCHICHTE 1 (1999) nr 1-2:

F. Marco-Simon - Sacrificios humanos en la Céltica antigua: entre el estereotipo literario y la evidencia interna 1-15; J. Rüpke - Apokalyptische Salzberge. Zum sozialen Ort und zur literarischen Strategie des "Hirten" des Hermas 148-160; J. Scheid - Hiérarchie et structure dans le polythéisme romain. Façons romaines de penser l'action 184-201.

18. ARCHIVO TEOLOGICO GRANADINO 69 (1999):

J. P. Monferrer - La "Leyenda del rey Abgaro» contenida en un manuscrito árabe oriental del siglo XVI, 107-140.

19. ATHENAEUM (1999) nr 1-2:

N. Adkin - Jerome on Tertullian: Epist. LVIII 10,1, 383-394; H. Leppin Constantinus II und das Heidentum 457-480.

20. AUGUSTINIANA 49 (1999) nr 1-4:

M.M. Brito Martins - Le projet herméneutique augustnien. II: Herméneutique et existence 5-55; E.L. Saak - The Creation of Augustinian Identity in the Later Middle Ages (I) 109-164, (II) 251-286; F.B.A. Asiedu - The Wise Man and the Limits of Virtue in "De beata vita»: Stoic Self-Sufficiency or Augustinian Irony 215-234.

21. AUGUSTINIANUM 39 (1999) nr 1-2:

K.H. Uthemann - Kaiser Justinian als Kirchenpolitiker und Theologe 5-83; J. Magne - „Carmina Christo quasi Deo” 85-95; A. Stewart-Sykes - The Integrity of the Hippolytean Ordination Rites 97-127; A. Camplani - La prima lettera festale di Cirillo di Alessandria e la testimonianza di P. Vindob. K 10157, 129-138; W. Mayer - Female Participation and the Late fourth-century Preacher's Audience 139-147; C. Munier - Problèmes monastiques et conciles Africains (a. 345-427), 149-168; A.M. Orselli-Modelli di santità e modelli agiografici nell'Occidente latino 169-185; A. di Berardino - Christianity on the Road 231-244, G.D. Dunn - Two Goats, two Advents and Tertullian's «Adversus Iudaeos» 245-264; S. Voicu - Note (pseudo-) Ippolitee 265-278; P. de Navascues - El Fr. 37 de Pablo de Samosata: una 
hipóstasis particular del Logos 275-293; N. Baglivi - Sulpicio Severo Chron. 2,34,1-5 e Paolino di Nola Epist. 31, 5, 295-310; N. Cipriani - La precettistica antica e la «Regola monastica» di S. Agostino 365-380; G. Folliet - Corrections apportées aux textes scripturaires $d u$ "De correptione et gratia" 381-405; B. Uvini - „Dispensatio” nel "De Trinitate» di Agostino di Ippona 407-465; E. Malaspina - Il cenobitismo missionario di Agostino di Canterbury e la „Peregrinatio” dei monaci celtici 467-504.

22. AUGUSTINUS 44 (1999) nr 172-175:

J. Oroz Reta - Aspectos teológicos de la conversión 7-28; J.S. Alexander Los godos en "De correptione Donatistarum» (Ep. 185), 29-34; S. Barbone - El número en Agustín 35-49; G. Bonner - La figura de Eva en la teología de Agustín 51-64; P. Burnell - Las funciones de la familia y de la sociedad civil en «La ciudad de Dios» de Agustín 65-70; R. Canning - El vocabulario de san Agustín sobre el bien común y el lugar del amor al prójimo 71-78; F.G Clancy - La cruz en los "Tractatus in Johannem» de Agustín 79-88; J.K. Coyle - Agustín, el maniqueísmo y la contracepción 89-97; S. Dale - El mausoleo de san Agustín. Un emblema de la supremacía papal 99-106; $\mathrm{G}$. Gillete - La gloria de la segunda venida de Cristo en las "Enarrationes in Psalmos» de Agustín 107-113; C. Harrison - Matrimonio y vida monástica en san Agustín: el lazo de la amistad 125-132; M.G.St.A. Jackson - Matrimonio e intervención divina en san Agustín 133-143; J.F. Kelly - El diablo en los comentarios de san Agustín sobre el Génesis 145-151; J.P. Kenney - San Agustín y el descubrimiento del misticismo 153-159; J.T. Lienhard - San Agustín y la dialéctica: defensor y a la defensiva 161-167; J. Lössl - Mateo 6, 13 en las obras últimas de Agustín 169-174; J. McWilliam - No pintado de otra pintura: análisis del "De quantitate animae» 76 de Agustín 175-181; E.C. Muller - La unidad de los libros octavo al décimo del "De Trinitate» de Agustín 183-191; A. Pic - San Agustín y la ,impietas” de Cicerón. Estudio del "De civitate Dei» 5, 9, 193-202; K.K. Raikas - „Audientia episcopalis”: problemática entre Estado e Iglesia en Agustín 203-223; P. Rigby - Justicia o tragedia: doctrina agustiniana del pecado original 225-236; M. Ruokanan Crítica teológica agustiniana de la política 237-240; A. Schlinder - Verificación o falsificación de observaciones psicohistóricas: el caso del suicido de Dido en "Confesiones» de san Agustín 241-246; M.A. Smalbrugge - Aspectos trinitarios en la doctrina agustiniana de la gracia 247-252; M. Spicer - La tradición tecnológica de la historia universal en el libro decimoquinto de «La ciudad de Dios» de Agustín 253-262; K.B. Steinhauser - Lectura agustiniana de la «Pasión de las santas Perpetua y Felicidad» 263-169, H. Stickelberger Karl Barth y Agustín: una amistad estrella 271-275; R.J. Teske - El sacrificio en "Réplica a un adversario de la Levy y de los Profetas» de Agustín 277281; N. J. Torcha - Implicaciones de la doctrina de la creación „de la nada” en la teología de san Agustín 283-290; F. van Fleteren - Gálatas 4, 24 y 1 
Corintios 10, 11, base bíblica de la exégesis de san Agustín 291-305; D. Weber - „Communis loquendi consuetudo”. Sobre la estructura de «El Génesis contra los maniqueos» de Agustín 307-313; V. Yudin - La posible línea de reconciliación entre todas hipótesis que sobre el origen del alma da Agustín en "El libre albedrío» 315-320.

23. BEITRÄGE ZUR NAMENFORSCHUNG 34 (1999) nr 1-4:

N. Wagner - Zu einigen Germanennamen bei Papst Gregor dem Großen 255-267.

24. BERLINER THEOLOGISCHE ZEITSCHRIFT 16 (1999) nr I -2:

J. Schröter - Religionsgeschichte des Christentums statt Theologie des Neuen Testaments? Begrundungsprobleme in der neutestamentlichen Wissenschaft 4-20; C. Colpe - Hintergründe der christlichen Zeitrechnung. Theologischer Begriff und politische Absicht im Kalender des Dionysius Exiguus 232-257.

25. BIBEL UND LITURGIE 72 (1999) nr 1-4:

T. Meurer, Ch. Uhring - „Was sagst du dazu, was denkst du, Abraham?”. Woody Allen und Origenes als Leser von Gen 22, 187-198.

26. BIBLISCHE NOTIZEN 97 (1999) nr 96-100:

(Nr 97) A. Vonach - Der Ton macht die Musik. Vorgaben und Normen der Exegese bei Hieronymus und in der rabbinischen Tradition 37-44.

27. BOGOSLOVNI VESTNIK 59 (1999) nr 1-4:

C. Sorč - Milenarizem nekoč in danes 327-347.

28. BULLETIN DE L'ASSOCIATION GUILLAUME BUDÉ (1 999) nr 1 -4: J. Boulogne - Apollonios de Tyane. Le mythe avorté d'une sagesse totale 300-310.

29. BULLETIN DE LITTERATURE ECCLÉSIASTIQUE 100 (1999) nr 1-4: J. R. Pouchet - Les trois orders de lumière intelligible chez Grégoire de Nazianze 19-30; D. Doucet - La problématique de la lumière chez Augustin 31-58; H. Crouzel - Saint Jérôme et ses amis toulousains 319-337; É. Griffe À travers les paroisses rurales de la Gaule du VI siècle 339-352.

30. BYZANTINISCHE ZEITSCHRIFT 92 (1999) nr 1-2:

H. Hunger - Romanos Melodos 1-9; D. Afinogenor - The Date of Georgios Monachos 437-447; M. Altripp - Überlegungen zum Synthronos der Hagia Sophia in Iznik/Nixaı 448-454; P. Grossmann - Besuche und Überfalle in der vorjustianischen Laura am Mosesberg 455-465.

31. BYZANTINOSLAVICA 60 (1999) nr 1:

L.S.B. Mac Coull - Who was Eusebius of Alexandria? 9-18; A. Avenarius Die Lehre des Johannes von Damaskus über die Ikone. Zum Problem des mittelalterlichen Symbolismus 19-35; A.D. Vakaloudi - Demonic-Mantic Practices: the Implication of the Theurgists and Their Power of Submission in the Early Byzantine Empire 87-113; J. Kostenes - Studies on the Great Palace in Constantinople. II: The Magnaura 161-182; V. Traimond - 
A propos de l'apport byzantin la gense de l'art russe 183-212; K. Horníčková - The Byzantine Reliquary Pectoral Crosses in Central Europe 213-249.

32. BYZANTION 69 (1999) nr 1-2:

R.W. Burgess - The Dates of the First Siege of Nisibis and the Death of James of Nisibis 7-17; E. Kislinger, D. Stathakopulos - Pest und Perserkriege bei Prokop: chronologische Überlegungen zum Geschehen 540-545; N. Koutrakou - Defying the Other's Identity: Language of Acceptance and Rejection in Iconoclastic Byzantium 107-118; B. Roosen - The Works of

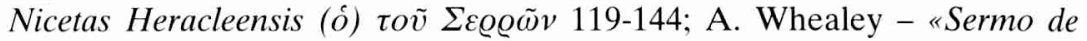
pseudoprophetis» of Pseudo-John Chrysostom: A Homily from Antioch under Early Islamic Rule 178-186; J. Vanderspoel - Corespondence and Corespondents of Julius Julianus 396-478; V. Somers - Quelques poèmes en l'honneur de $S$. Grégoire de Nazianze: édition critique, traduction et commentaire 528-564.

33. CAHIERS D'HISTOIRE 44 (1999) nr 1-4:

J.C. Decourt - Constitution d'une legende hagiographique: le „martyre” d'Irénée de Lyon 33-57.

34. CALVIN THEOLOGICAL JOURNAL 34 (1999) nr 1-2:

P.J. Leithart - Conjugating the Rites. Old and New in Augustine's Theory of Sings 136-147; S.H. Lancaster - Divine Relations of Trinity. Augustine's Answer to Arianism 327-346; B. Pitkin - Nothing but concupiscence. Calvin's Understanding of Sin and the Via Augustini 347-369.

35. THE CATHOLIC BIBLICAL QUARTERLY 61 (1999) nr 1-4:

K.A. Olson - Eusebius and the Testimonium Flavianum 305-322.

36. CERKIEWNY WIESTNIK 46(1999) nr l-4:

( Nr l) M. Dmitruk - Wielki Post w świetle świadectw patrystycznych i historycznych 54-62; (Nr 2) A. Kuźma - Homilie Paschalne św. Grzegorza Teologa 13-17; (Nr 3) M. Martynowicz - Biblijna myśl o raju i człowieku w literaturze patrystycznej 10-15; (Nr 4) J. Pagór - Skutki Wcielenia Jezusa Chrystusa wedtug św. Atanazego Wielkiego 3-7.

37. CHRISTIANITAS (1999) nr 1-2:

M. Lugmayr - Historia obrzędu Komunii świętej 141-152.

38. DER CHRISTLICHE OSTEN 54 (1999) nr 1-6:

F.R. Gahbauer - Gemeinsamer Glaube der Kirchen. Der Kirchenväter der katholischen und orthodoxen Kirche 111-127; Gemeinsamer Glaube der Kirchen. Die geistlichen Hymnendichter 187-195; G. Adler - „Sie ahmte das Leben der Engel nach” - Makrina, eine theologische Lehrerin im 4. Jahrhundert 249-258.

39. CHRIST TO THE WORLD 44 (1999) nr 1-6:

Pius X - St. Gregory I, the Great Evangelizer, translated by A.M. Sutton 13-23 (part I); 299-307 (part II); St. Bede - St. Gregory Concerning Mission Miracles (appendix) 23-24. 
40. CHRISTUS 46 (1999) $\mathrm{nr}$ 181-184:

$\mathrm{S}$. Augustin - Les vastes palais de la mémoire («Les Confessions» X, VI, 8 XVII, 26), trad. E. Tréhorel, G. Bouissou 35-37; O. Champion - L'homme de désir selon saint Augustin 163-171.

41. CHURCH HISTORY 68 (1999) nr 1-4:

S.J. Shoemaker - „Let Us Go and Burn Her Body”: The Image of the Jews in the Early Dormition Traditions 775-823.

42. CIENCIA TOMISTA 126 (1999) nr 408-410:

G. Celada Luego - El milenarismo antiguo, fragmento de la esperanza cristiana 513-542.

43. CLASSICAL PHILOLOGY 67 (1999) nr 1-4:

Ch.S. Mackay - Lactantius and the Succession to Diocletian 198-209.

44. THE CLASSICAL QUARTERLY 49 (1999) nr 1-2:

P.F. Alberto - Notes on Eugenius of Toledo 304-314; J. Geiger - Some Latin authors from the Greek East 606-617.

45. COLLECTANEA CISTERCIENSIA 61 (1999) nr 1-4:

A. Borias - Saint Benoît, ce maître et tendre père 81-103; A. Böckmann - La mystique bénédictine. Le spiritualité dynamique dans la «Règle» de saint Benoît 104-121; A. de Vogüé - Deux profils spirituels: Benoît de Nursie et Benoît d'Aniane 159-166; La Trinité dans la «Règle» de saint Benoît 241-247.

46. COLLECTANEA THEOLOGICA 69 (1999) nr 1-4:

(Nr l) K. Bardski - Księga Koheleta $w$ przekładach św. Hieronima. Diachroniczne aspekty pracy translacyjnej 33-46; A. Tronina - Najstarsze thmaczenia Pięcioksięgu 47-62; (Nr 4) T. Kołosowski - Śp. Ksiądz Profesor Jan Gliściński 139-151; Ojcowie Kościoła w internecie 142-144; Kolejny polski podrecznik patrologii 144-147; A. Filipowicz - Sympozjum patrystyczne „Kobieta w starożytności chrześcijańskiej” 147-151.

47. COMMUNIO (ESP) 32 (1999) nr 1-2:

V. Cudeiro González - La salvación del hombre en Platón en Jesucristo 117-141, 337-372.

48. COMMUNIO (PL) 19 (1999) nr 1-6:

(Nr 4) J. M. Silva Rosa - Kultura klasyczna a rodzace się chrześcijaństwo. Ciagłość czy zerwanie, tłum. ks. Lucjan Balter 16-30; I. Pereira Lamelas Spuścizna i aktualność Ojców Kościoła, tłum. ks. Lucjan Balter 31-43; M. Cristiani - Język klasyki, język chrześcijaństwa, tłum. Mieczysław Brzezinka 44-51; M.A. Crippa - Obrazy i symbole w Kościele w IV $i$ V wieku, tłum. ks. Franciszek Mickiewicz 52-68; G. Reale, M.T. Liminta - Chrześcijaństwo, kultura klasyczna a formacja młodzieży (wywiad), tłum. ks. Franciszek Mickiewicz 69-83; R. Calzecchi Onesti - Znaczenie języka greckiego, tłum. Mieczysław Brzezinka 84-93; (Nr 5) W.I. Eijk - Grecki ideat męstwa wobec chrześcijańskiej cnoty męstwa, tłum. ks. Franciszek Mickiewicz 22-38; J. Hermans - Męczeństwo: wzór chrześcijańskiego męstwa 
$i$ świętości, tłum. Emil Mendyk 77-84; D. Sampaio Barbosa - Świadectwo męczenników dawniej i teraz, thum. ks. Lucjan Balter 85-98.

49. COMMUNIO (USA) 26 (1999) nr 1-4:

P.J. Griffiths - The Gift and the Lie: Augustine on Lying 3-30; R. Darling Young - Ignatius of Antioch, ,Attaining the Father” 333-342.

50. COMMUNIO VIATORUM 41 (1999) nr 1-2:

G. Stemberger - Griechisch-römische und rabbinische Hermeneutik 101-112.

51. CONCILIUM (BRD) 35 (1999) nr 1-5:

E. Tamez - Das Jubeljahr in der jüdisch-christlichen Tradition 569-574.

52. CONCILIUM (FR) (1999) nr 279-283:

( Nr 283) E. Tamez - Le jubilé dans la tradition judéo-chrétienne 75-86.

53. CONNAISSANCE DES PÈRES DE L'ÉGLISE (1999) nr 73-76:

(Nr 73: Le Père) B. Studer - „Credo in unum Deum Patrem omnipotentem” 2-16; M.A. Vannier - Filiation et adoption divines 18-23; L. Brottier Comment prêcher la paternité de Dieu? Les résponses de Jean Chrysostome 24-38; J. Garcia - Dieu Père dans les commentaires de S. Augustin sur parabole de l'enfant prodigue (Lc 15, 11-31), 39-54; J. Seguin - La figure de Dieu Père dans le "De oratione dominica" de Grégoire de Nysse 55-61; (Nr 74: La Prédication) L. Brottier - Le prédicateur, émule du prophète ou rival de l'acteur? Jean Chrysostome: un pasteur déchiré entre ses auditeurs et son Dieu 2-19; J. Kecskeméti - L'homélie dramatisée dans la prédication grecque 20-32; H. Savon - Ambroise prédicateur 33-45; I. Bochet L'expérience spirituelle du prédicateur selon S. Augustin 46-53; A. OlivarSévère d'Antioche prédicateur 54-60; (Nr 75: La Pénitence) G. Kongs - Le sacrement de réconciliation: baptême-pénitence 2-10; $\mathrm{Ph}$. Rouillara - La discipline de la pénitence au temps des Pères (Certitudes, incertitudes et énigmes) 11-16; A. Fitzgerald - La pénitence dans l'Église ancienne 17-34; Pénitence et carême 35-42; L'oraison dominicale et le pardon des péchés 43-46; G. Lawless - La pardon mutuel dans la compréhension augustinienne du Notre Père (Mt 6, 12), 47-51; (Nr 76: La Trinité) B. Studer - Impulsions patristiques pour un renouvellement de la théologie trinitaire (première partie) 2-10; B. Pottier - La Trinité chez Grégoire de Nysse 11-21; M.A. Vannier - S. Augustin et la Trinité 22-32; M.O. Boulnois - «Du Père par le Fils dans l'Esprit»: une approche du paradoxe trinitaire chez Cyrille d'Alexandrie 33-44; J. Lison - La doctrine trinitaire de Grégoire Palamas 45-59.

54. CONTACTS 51 (1999) nr 1-4:

O. Clément - Chalcédoniens et non-chalcédoniens, quelques explications 193-205; G. Araman - L'Église orthodoxe et les Églises préchalcédoniennes 206-213; P.C. Sélis - L'Église syrienne orthodoxe 214-224; S.K. Pedersen L'Église orthodoxe d'Ethiopie 225-236; Ch. Chaillot - Vie et orthodoxie de L'Église copte 237-263; K. Beledian - L'Église arménienne, gardienne fidèle 264-276. 
55. CRISTIANESIMO NELLA STORIA 20 ( 1999) nr 1-3:

P. Laurence - Albine. La conversion d'une aristocrate romaine au sanctum propositum 257-274; G. Filoramo - Profezia e politica nelle "Storie monastiche» di Cirillo di Scitopoli 521-544.

56. CURRENDA 149 (1999) nr 1-4:

A. Żurek - Gdy do Boga zwracamy się „Ojcze” [w tradycji patrystycznej] 109-119; Czy można świętować dzień Pański tak jak pierwsi chrześcijanie, czyli o niedzieli abstrakcyjnie i konkretnie 254-261.

57. DIDASKALIA 29 (1999) nr 1-2:

M. Clemente - Razão e Fé no pensamento de santo Agostinho 249-255.

58. THE DOWNSIDE REVIEV (1999) nr 406-409:

J. Williams - The apophatic Theology of Dionysius the Pseudo-Areopagite (I) 157-172, (II) 235-250; J. Fortin - The Presence of God: A linguistic and thematic Link between the Doctrinal and Liturgical Sections of «The Rule of Saint Benedict» 293-305.

59. DUCHOVNÝ PASTIER 80 (1999) nr 1:

G. Coppa - Maria u Církevnich Otcü. (Homilia, Svaté Hory) 12-18; J. Vateha - Poslušnost'v Kratkych pravidlách Sv(ätého) Bazila vo svetle modernej teológie a antropológie 18-22.

60. EARLY MEDIEVAL EUROPE 8 (1999) nr 1-3:

C. Cardelle de Hartmann - The textuall transmission of the Mozarabic Chronicle of 754, 13-29; G. Halsall - Movers and Shakers: the barbarians and the Fall of Roma 131-145; R.W. Mathisen - Sigisvult the Patrician, Maximinus the Arian, and political Stratagems in the western Roman Empire ca 425-440, 173-196; (Nr 3) K. Cooper - The martyr, the „matrona” and the bishop: the matron Lucina and the politics of martyr cult in fifth-and sixth-century Rome 297-317.

61. ECCLESIA ORANS 16 (1999) nr 1-4:

E. Carr - L',Hodie” nei sermoni ritmici di Giacobbe di Serug per le grandi feste 17-28; M. Nin - Discorso i sulla Pasqua di san Gregorio Nazianzo 29-35; G. Ramis - Liturgia Hispano-Mozarabe. Boletin Bibliografico (1993-1998), 123-131.

62. EMERITA 67 (1999) nr 1-2:

L. Ferreres - La tradición indirecta en dos restituciones al texto del PseudoCipriano «De laude martyrii» 289-294.

63. EPHEMERIDES LITURGICAE 113 (1999) nr 1-6:

F. Manns - Pâque juive et Pâque chrétienne 31-46; S. Parenti - Preghiere delle «Constituzioni Apostoliche» in alcuni eucologi italo-greci del medioevo 47-52; F. Manns - Une tradition judéo-chrétienne a Rome 228-231; E. Mazza - L'uso di „sacramentum” nella Lettera 10, 96 di Plinio il Giovane: un confronto con la liturgia battesimale 466-480.

64. EPHEMERIDES MARIOLOGICAE 49 (1999) nr 1-3: 
L.F.M. Seco - Mariología y teología patrística 379-400.

65. EPHEMERIDES THEOLOGICAE LOVANIENSES 75 (1999) nr 1-4:

J. Leemans - The critical Edition of „Athanasius Werke” continued 133-141;

B. Dehandschutter - The Martyrdom of Polycarp and the outbreak of Montanism 430-437.

66. ESTUDIO AGUSTINIANO 34 (1999) nr 1-3:

P. de Luis - Estructura de la Regla de San Agustín (V) 5-29, (VI) 219-247, (VII) 539-576.

67. ESTUDIOS BÍBLICOS (1999) nr 1-4:

U.Á. Fernández - Fuentes bíblicas y patrísticas de algunos títulos cristológicos en el anónimo «De ortu obitu patriarcharum» (c. 780), 711-734.

68. ÉTUDES BALKANIQUES (1999) nr 1-2:

P. Stefanov - History and essence of manichaeism 24-33; A. Omarchevsky Saint Anatolius, patriarche de Constantinople (450-458), 34-43.

69. ÉTUDES GRÉGORIENNES (1999) nr 27:

P. Bernard - La schola cantorum romaine et les échanges liturgiques aves la Gaule au VI siècle 61-120.

70. EVANGELISCHE THEOLOGIE 59 (1999) nr 1-6:

O. Skarsaune - Altkirchliche Christologie - jüdisch / unjüdisch? 267-285.

71. FAITH AND PHILOSOPHY 16 (1999) nr 1-4:

D.P. Hunt - On Augustine's way out 3-26.

72. FINSK TIDSKRIFT 245-246 (1999) nr 1-9:

K.G. Sandelin - Filon från Alexandria och den grekisk-romerska kulturen 367-380.

73. FREIBURGER UNIVERSITÄTSBLÄTTER (1999) nr 143-146:

(Nr 146) R. Warland - Die Gegenwart der Antike in der mittelbyzantinischen Kunst 77-85.

74. FREIBURGER ZEITSCHRIFT FÜR KATHOLISCHE THEOLOGIE 46 (1999) nr 1-3:

M. von Perger - Wie Maximus Confessor und Augustinus die Teophanie verstanden. Zu Eriugena «Peri physeon»I 449A-450B, 35-51; K. Ubl Verantwortlichkeit und autonomes Handeln. Zur Entwicklung zweiter Freiheitsbegriffe von Augustinus bis Thomas von Aquino 79-114.

75. HAGIOGRAPHICA (1999) nr 6:

T. Head - Discontinuity and Discovery in the Cult of Saints: Apulia from Late Antiquity to the High Middle Ages 171-211; G.N. Verrando - Frammenti e testi agiografici isolati in manoscritti italiani 257-307.

76. HARVARD THEOLOGICAL REVIEW 92 (1999) nr 1-4:

R. Werline - The Transformation of Pauline Arguments in Justin Martyr's «Dialogue with Trypho»79-93.

77. HERMENEIA 15 (1999) nr 1-4:

(Nr 1) E. Sauser - Der hl. Ambrosius von Mailand 6; (Nr 3) Der Heilige 
Spyridon von Trimithous 6; D. Oikonomou - Frühe christliche und byzantinische Musik. Geschichte und Ausführung, übersetzt K. Keller 31-38; N. Thon - Der hl. Ioustinos der Martyrer und Philosoph 6; (Nr 4) M. Aidan - Heilige des 1. Jahrtausends in Britannien und Irland, übersetzt K. Keller 11-19.

78. HERMES 127 (1999) nr 1-4:

M.G. Schmidt - "Ambrosii carmen de obitu Probi». Ein Gedicht des Mailänden Bischofs in epigraphischen Überlieferung 99-116; H. Tränkle - Textkritische Bemerkungen zu Augustins "Confessiones» 208-236.

79. HISPANIA SACRA 51 (1999) nr 103-104:

F. Hubeñák - El hispano Teodosio y la cristianización del Imperio 5-42; H. Gallego Franco - El vino en los Concilios Hispanovisigodos: su contexto socioeconómico y cultural 43-53; J.C. Lara Olmo - El relato del traslodo de los santos mártires Jorge, Aurelio y Natalia: un valioso escrito hagiográfico y documental histórico de mediados de siglo IX, 55-89; L.A. Garcia Moreno Monjes y profecías cristianas próximo - orientales en Al.-Andalus del siglo IX, 91-100; A. Barcula - La moralización de la vida pública en los reinos bárbaros. El proyecto de Teodorico y Casiodoro 413-445.

80. HISTORIA 48 (1999) $\mathrm{nr} 1-4$ :

W. Portmann - Die politische Krise zwischen den Kaisern Constantius II. und Constans 301-329.

81. HISTORISCHE ANTHROPOLOGIE 7 (1999) nr 1-3:

S. Elm - «Sklave Gottes» - Stigmate, Bischöfe und anti-häretische Propaganda im vierten Jahrhundert 345-363.

82. IRÉNIKON 72 (1999) nr 1-2:

Ch. Schütz - «Le Christ - Seigneur» dans la Règle de saint Benoît 42-72.

83. JOURNAL OF EARLY CHRISTIAN STUDIES 7 (1999) nr 1-4:

Ch.E. Hill - The «Epistula Apostolorum»: An Asian Tract from the Time of Polycarp 1-53; R. Valantasis - Is the Gospel of Thomas Ascetical? Revisiting an Old Problem with a New Theory 55-81; B.E. Bowe - Dancing into the Divine: The Hymn of the Dance in the "Acts of John" 83-104; A.S. Jacobs A Family Affair: Marriage, Class, and Ethics in the Apocryphal Acts of the Apostles 105-161; G. Kreahling McKay - The Eastern Christian Exegetical Tradition of Daniel's Vision of the Ancient of Days 139-161; D. Brakke Parables and Plain Speech in the Fourth Gospel and the "Apocryphon of James» 187-218; J. Behr - The Rational Animal: A Rereading of Gregory of Nyssa's "De hominis opficio» 219-247; T.S. De Bruyn - Flogging a Son: The Emergence of the „pater flagellans” in Latin Christian Discourse 249-290; S. Weingarten - Was the Pilgrim from Bordeaux a Woman? A Reply to Laurie Douglas 291-297; S.R. Holman - The Hungry Body: Famine, Poverty, and Identity in Basil's Hom. 8, 337-363; Victricius of Rouen - "Praising the Saints». Introduction and Translation G. Clark 365-399; D.G. Hun- 
ter - Vigilantius of Calagurris and Victricius of Rouen: Ascetics, Relics, and Clerics in Late Roman Gaul 401-430; B.E. Daley - The Cappadocian Fathers and the Rhetoric of Philanthropy 431-461; J.C. Poirier - Montanist PepuzaJerusalem and the Dwelling Place of Wisdom 491-507; E. Engelbrecht God's Milk: An Orthodox Confession of the Eucharist 509-526; R.M. Jensen - The Economy of the Trinity at the Creation of Adam and Eve 527-546; T. Vivian - Monks, Middle Egypt, and „,Metanoia”: The "Life of Phib» by Papohe the Steward (Translation and Introduction) 547-571; G. Shaw Neoplatonic Theurgy and Dionysius the Areopagite 573-599.

84. THE JOURNAL OF JURISTIC PAPYROLOGY 29 (1999):

A. Łajtar, E. Wipszycka - SB IV 7315, Texte mentionnant des martyrs qui ont recu „deux couronnes”: la plus ancienne inscription chrétienne d'Égypte $67-73$.

85. THE JOURNAL OF ECCLESIASTICAL HISTORY 50 (1999) nr 1-4:

A. Stewart-Sykes - The Original Condemnation of Asian Montanism 1-22; P. McKechnie - Christian Grave-Inscriptions from the Familia Caesaris 427 441.

86. JOURNAL OF RELIGIONS ETHICS 27 (1999) nr 1-4:

Ch.T. Mathewes - Augustinian Anthropology: «Interior intimo meo»195-221.

87. JOURNAL OF THE HISTORY OF PHILOSOPHY 37 (1999) nr 1-4:

S. Pessin - Hebomads: Boethius Meets the Neo-Pythagoreans 29-48.

88. KERYGMA UND DOGMA 45 (1999) nr 1-4:

K. Fitschen - „Nihil innovetur”: „opto omnes in ecclesiam regredi”. Bischof Cyprian von Karthago im Spannungsfeld von Amtstheologie, Seelsorge und Gemeindeaufbau 64-85.

89. KU DOJRZAŁOŚCI W KULTURZE RELIGIJNEJ 5 (1999) nr 1-6:

(Nr 4) Jan Paweł II - List Apostolski na 1500 rocznicę narodzin św. Benedykta 21-34.

90. KWARTALNIK FILOZOFICZNY 27 (1999) nr 1-4:

(Nr 3) M. Manikowski - Pseudo-Dionizy Areopagita: myślenie symboliczne 39-53; J. Satorowicz - Boecjusz w Atenach. Zamrożony błąd historyczny $55-65$.

91. LATERANUM 65 (1999) nr 1-2:

C.L. Rosetti - Speranza universale e possibilità dell' inferno. Riflessioni per una teologia ortodossa dell' Apocatastasi 131-137.

92. LEBENDIGES ZEUGNIS 54 (1999) nr 1-4:

E. Reil - ,...daß wir auf Erden niemanden unseren Lehrer nennen”. Selbstverständnis und Sendung des Lehrers nach Augustinus Schrift "De magistro» 90-99.

93. LEGNICKIE WIADOMOŚCI DIECEZJALNE 8 (1999) nr 1-4:

(Nr 2) L. Rzodkiewicz - Jezus Chrystus jako antyczny Ideat PedagogaWychowawcy wedtug Klemensa Aleksandryjskiego 62-75. 
94. LINGUA AC COMMUNITAS 9 (1999):

T. Sahaj - Wpływ poglądów świętego Augustyna na postrzeganie śmierci w kulturze europejskiej 211-221.

95. LITERATURE \& THEOLOGY 13 (1999) nr 1-4:

S.E. Hill - (Dis) Inheriting Augustine: Constructing the alienated Self in the autobiographical Works of Paul Monette and Mary Daly 149-165.

96. LITURGIA SACRA 5 (1999) nr 1-2:

W. Głowa - Wielki post w świetle homilii wielkopostnych z Liturgii godzin 55-65; J. Wójciak - Exultet: wielkanocny hymn Kościoła. Geneza i morfologia 91-103; I.H. Siekierka - Najstarsze świadectwa notacji chorału gregoriańskiego 105-119.

97. LUMEN VITAE 54 (1999) nr 1-4:

F. Manns, La symbolique animale évoque-t-elle l'Espirit Saint? 255-267.

98. LUX VERITATIS (1999) $\mathrm{nr} 1$ :

S. Strękowski - Wezwanie do nawrócenia u apologetów chrześcijańskich II-III wieku 184-195; R. Kurek, M. Nowik - Miejsce i rola pustyni w życiu duchowym anachoretów 196-204; J.W. Czartoszewski - Uniwersalne czynniki jednoczace życie wspólnotowe zawarte w regule św. Benedykta 222-230; M. Mejor - Odkrycie zaginionych Homilii św. Augustyna 252-255; Biblioteka Orygenesa 256-269.

99. LA MAISON DIEU (1999) nr 217-220:

(Nr 219) R. le Gall - A l'unisson des Pères. L'influence durable de Dom Guéranger sur la réforme liturgique 141-186.

100. MEANDER 53 (1998) nr 1-6:

M. Cytowska - Poemat Paulina z Pelli 277-286; J. Mierzejewska - Pojęcie agape $w$ «Stromatach» Klemensa Aleksandryjskiego 253-260.

101. MEANDER 54 (1999) nr 1-6:

R. Wiśniewski - Pogaństwo, herezja i diabeł w świecie św. Marcina i Sulpicjusza Sewera 59-78; R. Dyrcz - Kilka uwag o przemianach i znaczeniu kultu Asklepiosa w okresie późnego antyku 257-265; M.J. Leszka - Cesarzowa Ariadna 267-278; M. Winiarczyk - Starożytność klasyczna i chrześcijaństwo antyczne - wzajemne kontakty obydwu dyscyplin oraz ich stosunek do religioznawstwa 279-289; $\mathrm{H}$. Szelest - Utwór Auzoniusza «De herediolo» 349-356; K. Maksymiuk - Zatożenia polityki propagandowej Septymiusza Sewera na przykładzie tytułu Julii Domny „mater castrorum” 449-455; D. Brodka - „Teologia zwycięstwa” cesarzy chrześcijańskich $a$ «Historia ecclesiastica» Rufina z Akwilei 457-464; M.J. Leszka - Lupicyna-Eufemia: żona Justyna I, 555-562

102. MEDIUM AEVUM 68 (1999) nr 1-2:

T. Adams - „Pur vostre cor su jo em paine”: the Augustinian subtext of Thomas's Tristan 278-291.

103. MÉLANGES DE L'ÉCOLE FRANÇAISE DE ROME 111 (1999) nr 1 


\section{(Moyen Âge):}

R. Rea - Il Colosseo. Destrutturazione e riuso tra IV e VIII secolo 183-195;

A. Augenti - Il potere e la memoria. Il Palatino tra IV e VIII secolo 197207; M. Cecchelli - Dati da scavi recenti di monumenti cristiani. Sintesi relativa a diverse indagini in corso 227-251.

104. MIEJSCA ŚWIĘTE 28 (1999) nr 1-12:

(nr 4) J. Naumowicz - Syryjscy asceci, 40-41.

105. MILLTOWN STUDIES 44 (1999) nr 1-2:

N. Madden - Maximus Confessor: The three Laws 89-102.

106. MISCELÁNEA COMILLAS 57 (1999) nr 110-111:

A. Valastro Canale - „Omnia in mensura et numero et pondere fecisti” (Sap 11, 21). Notas acerca de «Etymologiae» III 7, 5-6, 483-499.

107. MNEMOSYNE 52 (1999) nr 1-6:

J.W. Drijvers - Strabo 17. 1. 18 (801C): Inaros, the Milesians and Naucratis 16-22.

108. MÓWIĄ WIEKI (1999) nr 1-12:

(Nr 12) P. Janiszewski - Era dionizyjska a rzeczywista data narodzin Jezusa 7-11.

109. NEDERLANDS THEOLOGISCH TIJDSCHRIFT 53 (1999) nr 1-4:

P.W. van der Horst - , Leer hem de Psalmen, want ik neb hem nodig!”: De bijbel in het werk van Cyrillus van Skythopolis 274-285.

110. NEW TESTAMENT STUDIES 45 (1999) nr 1-4:

P. Borgen - Two Philonic Prayers and their Contexts: An Analysis of Who is the Heir of «Divine Things» (Her.) 24-29 and «Against Flaccus» (Flac.) 170-175, 291-309.

111. NICOLAUS 26 (1999) nr 1-2:

R. Grégoire - Il problema trinitario nella teologia altomedievale occidentale 169-186; N. Bux - L'inserzione del Filioque nelle liturgie Gallicana e Romana. Una caso di arrichimento del simbolo 231-243; E. Lanne - La Processio dello Spirito Santo nella tradizione occidentale 245-260; D. Popescu - Il problema del Filioque: Ekporeusis e Processio. Il metodo teologico 261-271; M. Falla Castelfranchi - La teologia trinitaria: aspetti iconologici e iconografici. Le origini e il suo sviluppo in arca bizantina 285-315.

112. NOWY FILOMATA 3 (1999) nr 1-4:

D. Zołoteńki - Od Galii Rzymskiej do Galii Frankijskiej - podbój czy integracja 127-134; R. Dyrcz - Wokót zburzenia przez. Konstantyna Wielkiego asklepiejonu w Ajgaj w Cylicji w 331 r. po Chr. 195-210.

113. NOVUM TESTAMENTUM 41 (1999) nr 1-4:

D.M. Scholer - Bibliographia gnostica: Supplementum II/2 58-93; E.J. Schnabel - Die ersten Christen in Ephesus. Neuerscheinungen zur frühchristlichen Missionsgeschichte 349-382. 
114. ORIENTALIA CHRISTIANA PERIODICA 65 (1999) nr 1-2:

M. van Esbroeck - Un discours inédit de saint Germain de Constantinople sur la Croix et les Icônes 19-51; P. Argárate - La Luz de tu Postro: Teología de la „Gloria” en Diádoco de Fótice 257-278; R.F. Taft - Byzantine Communion Rites. I: The Early Ritual of Clergy Communion 307-345.

115. ORTHODOXES FORUM 13 (1999) nr 1-2:

M. Wallraff - Das siebte ökumenische Konzil (Nikaia 787)? In der lutherischen Kirchengeschichtsschreibung 21-30; G. Martzelos - Die Anfänge und die Voraussetzungen des Filioque in der theologischen Überlieferung des Abendlandes 31-45; K. Nikolakopoulos - Grundprinzipien der orthodoxen patristischen Hermeneutik 171-185; Ch. Térézis - La notion de matière chez Plotin et Grégoire de Nysse 187-202.

116. OSTKIRCHLICHE STUDIEN 48 (1999) nr 1-4:

E.M. Synek - Der Frauendiakonat der Alten Kirche und seine Rezeption durch die orthodoxen Kirchen 3-31.

117. PARAGRANA 8 (1999) nr 1-2:

G. Tzartzas - Askese im frühen Christentum. Der Bios Antonius als Paradigma 33-45.

118. PASTORES (1999) nr 2-5:

(Nr 2) J. Naumowicz - Dzielić z uczniami swoje życie 72-81; M. Starowieyski - Bóg działa przez wszystkich kapłanów 122-131; (Nr 3) J. Naumowicz - Milczenie ust i milczenie serca 121-128; (Nr 4) J. Naumowicz Strzec swego sumienia 120-125; ( Nr 5) J. Naumowicz - Bezżenni dla królestwa niebieskiego 114-120.

119. PENSAMIENTO 55 (1999) nr 211-213:

L.E. Bacigalupo - La confrontacion de San Agustín con el escepticismo y sus probebles vínculos con la moral provisional de Descartes 127-144.

120. PHILOLOGUS 143 (1999) nr 1-2:

P.A. Deproost - Le martyre chez Prudence: sagesse et tragédie. La réception de Sénèque dans le "Peristephanon Liber»161-180.

121. PHILOSOPHY TODAY 43 (1999) nr 1-4:

J. Protevi - Inventio and the unsurpassable Metaphor: Ricoeur's Treatment of Augustine's Meditation 86-94.

122. POLONIA SACRA 3 (1999) nr 4-5:

J.W. Żelazny - Pneumatologia Teodoreta z Cyru w «Komentarzu do 1 i 2 Listu do Koryntian» 233-246.

123. POSITIONS LUTHÉRIENNES 47 (1999) nr 1-4:

A. Greiner - Un regard luthérien sur la Règle de Saint Benoît 259-283.

124. PREMISLIA CHRISTIANA 8(1999):

J. Edling - Cielesno-duchowa struktura człowieka $w$ swym wymiarze historyczno-rewelatywnym wedtug św. Augustyna 197-220; Rewelatywny charakter czasu pierwotnej szczęśliwości i czasu upadku człowieka $w$ ujęciu 
św. Augustyna 221-236; A. Świtkiewicz - Doktrynalne źródła nauki św. Grzegorza Palamasa 373-391.

125. THE PRINCETON SEMINARY BULLETIN 20 (1999) nr 1-3:

N. Wolterstorff - Christian political Reflection: Diogenetian or Augustinian 150-168.

126. PRZEGLĄD RELIGIOZNAWCZY (1999) nr 191-194:

(Nr 193/194) A. Świtkiewicz-Blandzi - Dzieje filozoficznego i teologicznego sporu wokót doktryny św. Grzegorza Palamasa na tle relacji państwoKościót w XIV-wiecznym Bizancjum 3-15.

127. PRO ECCLESIA 7 (1999) nr 1-4:

A. Golitzin - Liturgy and mysticism. The Experience of God in Eastern Orthodox Christianity 159-186; D. Keating - The Baptism of Jesus in Cyril of Alexandria. The Recreation of the Human Race 201-222; A. Russel Christman - „What did Ezekiel see?”. Patristic Exegesis of Ezekiel 1 and Debates about God's Incomprehensibility 338-363.

128. QUESTIONES LITURGIQUES 80 (1999) nr 1-4:

J.A. Farazza - Chaos contained: The Construction of Religion in Cyprian of Carthage 81-90; L. Beauduin - La liturgie et les Conciles d'Éphèse et de Chalcèdoine 196-203; B. Capelle - L'anaphore de Sérapion. Essai d'exégèse 235-249; E. Moeller - Paulin II d'Aquilée (756-802) et l'hymne "Ubi caritas» du mandatum du Jeudi-saint 295-301; A. Verheul - La prière eucharistique dans la Didachè 337-347; La prière eucharistique de Addaï et Mari 348-357; Les prières eucharistiques dans les "Constitutiones Apostolorum» 358-373; La prière eucharistique dans l'Euchologe de Sérapion 374383.

129. RASSEGNA DI TEOLOGIA 40 (1999) nr 1-6:

V. Grossi - S. Agostino, la Bibbia e il postmoderno 857-877.

130. RECHERCHES AUGUSTINIENNES (1999) nr 31:

P. Dufraigne - Quelques aspects de'l'aduentus in mentem d'Hippolyte de Rome à Grégoire le Grand 3-87; P. Géhin - Le dossier macarien de l'Atheniensis gr. 2492, 89-147; F.J. Leroy - Les 22 inédits de la catéchèse donatiste de Vienne. Une edition provisoire 149-234; W. Löhr - Pelagius' Schrift "De natura». Rekonstruktion und Analyse 235-253.

131. RECHERCHES DE THÉOLOGIE ET PHILOSOPHIE MÉDIÉVALES 66 (1999) nr 1-2:

J.R. Meyer - Athanasius' Son of God Theology 225-253.

132. RELIGIÓN Y CULTURA 45 (1999) nr 1-4:

Á. Brahona Plaza - Girard y San Agustín 495-526; A. Guijarro Mayor Theodosio o el providencialismo práctico. San Agustín y la política teodosiana 527-550; S. Mañero - La ,filosofia cristiana” como ,forma de vida”: Santa Catarina de Alejandría 551-574; A. Jiménez Manzanas - Eros y belleza en San Agustín 621-635. 
133. REVISTA AGUSTINIANA 40 (1999) nr 1-3:

M.J. Aldana García - Notas sobre la significacion del término „Martyrium” en la obra de San Eulogio 89-102; M.A. Vannier - Les avatars de l'augustinisme 133-142; M.Á. Navarro Girón - "La Ciudad de Dios» de San Agustín. Materiales para el estudio (II) 197-263; J. Anoz - Sermones inéditos de San Agustín para la conversión de paganos y donatistas (VI) 319-376; J.M. Magaz - La herejía en la «Historia Eclesiastica» de Eusebio de Cesarea 479-532; J.G. Birlanga Trigueros - Entre Tagaste y París. Dos modernas antropologias de compromiso: Agustín de Hippona y Jean Paul Sartre 547-576; T.C. Madrid - El ministerio pastoral según San Agustín 653713; M.Á. Navarro Girón - «La Ciudad de Dios» de San Agustín. Materiales para el estudio (III) 715-769; J. Cercós Soto - Orígenes y Boecio: apuntes sobre el mal y la muerte 955-963; M.J. Aldana García - Valores semánticos de la confesión en la obra de San Eulogio: verbo „confiteor” 965-979; S.J.G. Sánchez - Le culte chrétienne dans les maisons privées durant les premiers temps de l'Eglise 1009-1062; M.Á. Navarro Girón - «La Ciudad de Dios» de San Agustin. Materiales para el estudio (IV), 1125-1165.

134. REVISTA ESPAÑOLA DE TEOLOGIA 59 (1999) nr 1-4:

J.C. Rivadeneira Cockburn - Dimensión litúrgica de la espiritualidad en San Ignacio de Antioquía según la carta a los Efesios 103-121.

135. REVISTA TEOLOGICÃ 9 (1999) nr 1-4:

(Nr 1) I. Ielciu - Raportul dintre „Așezămintele mânăstirești” si „Convorbirile duhovnicești”. Sursele și aptitudinile literare ale Sfântului Ioan Cassian 36-43; S. Mandache - Credință și filosofie în «Stromatele»lui Clement Alexandrinul 70-88; P.I. Ilea - Principiul , recapitulării” in Hristos, in teologia și practica misionară ortodoxă 108-125; D. Hrib - Beda Venerabilul, precursor al reformei cardingiere 126-144; ( $\mathrm{Nr} 2$ ) L. Grozea - Gnosticismul: concept, origini, caracteristici, delimitare 67-88; I.S. Muresan - Viața creștinilor în teritoriile cucerite de musulmani în secolele VII-IX, 89-100; Sfãntul Grigorie Palama - Despre inviere și despre mironosite, trad. asist Ciprian Streza 105110; (Nr 3) I.M. Ielciu - Principalele etape ale biografiei unul mare îndrumător duhovnicesc al Apulsului: sciful Ioan Cassian 16-60; N. Dumitrascu Conceptia despre sufletul uman al lui Hristos in primele veacuri crestine 6168; N. Moșoiu - Metamorphosis, metamorphote-schimbarea la faţă a lui Hristos pe Tabor, dovada anticipată despre lumina sfintei Treimi, ce va iradia din trupul Său înviat și al tuturor celor ce-și vor arăta credința prin faptele lor 69-80; ( $\mathrm{Nr} 4$ ) S. Papadopoulos - Teologie și limbaj (partea a II-a, trad. Pr. dr. Ilie Frăcea) 28-76; N. Chifăr - Relațiile politico-religioase dintre Roma și Constantinopol la începtul secolului al VIII-lea 88-99.

136. REVUE BÉNÉDICTINE 109 (1999) nr 1-4:

M. Gorman - Bede's VIII "Questiones» and Carolingian Biblical Scholarship 32-74. 
137. REVUE BIBLIQUE 106 (1999) nr 1-4:

Y. Hirschfeld - Imperial Building Activity during the Reign of Justinian and Pilgrimage to the Holy Land in Light of the Excavations on Mt. Berenice, Tiberias (Planches I-IV) 236-249.

138. REVUE DES ÉTUDES AUGUSTINIENNES 45 (1999) nr 1:

Ch. Ingremean - Minucius Felix et ses «sources»: le travail de l'écrivain 3-20; J. Elfassi - Le sermon 150 de saint Augustin. Édition critique et tentative de datation 21-50; M.P. Foley - Cicero, Augustine, and the philosophical Roots of the Cassiciacum Dialogues 51-77; I. Perczel - Une theólogie de la lumière: Denys' l'Aréopagite et Évagre le Pontique 79-120; M. Gorman - From Isidore to Claudius of Turin: The Works of Ambrose on Genesis in the Early Middle Ages 121-138.

139. REVUE DES ÉTUDES JUIVES 158 (1999) nr 1-4:

N. Bélayche - „Dimenticare... Gerusalemme”. Les paganismes à Aelia Capitolina du II $I^{e}$ an $I V^{e}$ siècle de notre ère 287-348.

140. REVUE D'HISTOIRE ECCLÉSIASTIQUE 94 (1999) nr 1-4:

L.S.B. MacCoull - Gregory Thaumaturgus' Vision Re-envisioned 5-14.

141. REVUE D'HISTOIRE ET DE PHILOSOPHIE RELIGIEUSES 79 (1999) nr 1-4:

P. Maraval - Apocalypse 3, 20 dans l'interprétation patristique des III et $I V^{e}$ siècles 57-64; J.M. Prieur - La croix vivante dans la théologie chrétienne du II siècle 435-444.

142. REVUE D'HISTOIRE DES RELIGIONS 216 (1999) nr 1-4:

N. Gradowiz Pancer - Le «panoptisme» monastique. Structures de surveillance et de contrôle dans le cénobitisme occidental ancien ( $V^{e}-V I^{e}$ siècles) 167-192.

143. REVUE DE THÉOLOGIE ET DE PHILOSOPHIE 131 (1999) nr 1-4: E. Bons - Le livre de Quohéleth. Les "paradigmes» de l'histoire de son interprétation chrétienne 199-295.

144. REVUE THÉOLOGIQUE DE LOUVAIN 30 (1999) nr 1-3:

A. Mattei - Baptême hérétique, ecclésiologie et Siracide 34, 25. Note sur l'influence de Cyprien dans un texte de Pacien de Barcelone 180-194.

145. RHEINISCHES MUSEUM FÜR PHILOLOGIE 142 (1999) nr 1-4:

J. Doignon - Augustin (Lib. arb. 3,3,5) et Cicéron sur les Épicuriens et la Fortune 83-87.

146. RHETORICA 17 (1999) nr 1-4:

A.W. Astell - Cassiodorus" "Commentary on the Psalms» as an Ars rhetorica 37-75.

147. RICERCHE, CONTINUITÀ E RINNOVAMENTO 19 (1999) 59-62:

(Nr 61) G. Rocchiccioli - Uno scolopio ignoto studioso di patrologia 56-58.

148. RICERCHE STORICO BIBLICHE 11 (1999) nr 1-2:

(Nr 2) C. Gianotto - Farisei e la legge negli scritti gnostici 171-187; 
G. Visonà - Sopravvivenze farrisaiche nel Dialogo di Giustino con l'ebreo Trifone? 189-214.

149. RICERCHE TEOLOGICHE 10 (1999) nr 1-2:

L. Perrone - Origene, il «Peri Archôn» e la tradizione origeniana in Occidente 339-343; M. Maritano - „Dio Padre” secondo i Padri della Chiesa 349-369.

150. RIVISTA CISTERCIENSE 16 (1999) nr 1-3:

B. Stockill - Il tempo pasquale nella «Regola» di san Benedetto 41-54.

151. RIVISTA DI ARCHEOLOGIA CRISTIANA 75 (1999) nr 1-2:

F. Bisconti, M.P. Del Moro - Via Latina 135: cronaca di un intervento di urgenza. Un'area catacombale recuperata al II miglio della via Latina 11-94; R. Giulliani, F.M. Tomassi - Recenti indagini nella catacomba della ex vigna Chiaraviglio sulla via Appia antica. Relazione delle campagne di scavo nella regione E (1994-1996), 95-231; B. Mazzei - Il cubicolo dell'Annunciazione nelle catacombe di Priscilla 233-280; J. Yamada L'arcosolio dell'Hermes-psicopompo nel cimitero di S. Sebastiano: qualche riflessione alla luce dei recenti restauri 281-305; F.A. Bauer - La frammentazione liturgica nella chiesa romana del primo medioevo 385446; E. Jastrzębowska - Ephesos und Chersonesos in Spätantike und frühbyzantinischer Zeit. Eine vergleichende topographische Studie 475-520; P. Liverani - Dalle aedes „Laterani” al Patriarchio lateranense 521-549; D. Mazzoleni et alii - Le iscrizioni della catacomba di Calepodio 597-694; A. Nestori - Riflessioni sul luogo di culto cristiano preconstantiniano 695-709; A.M. Panattoni - Alcune considerazioni sugli epigrammi cristiani di Roma in lingua greca 711-717.

152. RIVISTA DI CULTURA CLASSICA E MEDIOEVALE 41 (1999) nr 1-2:

A.M. Guerrieri - Modelli di santità nella «Historia Ecclesiastica» di Beda 245-263.

153. RIVISTA DI STORIA DELLA CHIESA IN ITALIA 53 (1999) nr 1:

I. Ramelli - Annotazioni sulle origini del Cristianesimo in Sicilia 1-15.

154. RIVISTA TEOLOGICA DI LUGANO 4 (1999) nr 1-3:

M. Brun - Les religions humaines selon les Pères de l'Église 205-225.

155. ROCZNIKI HUMANISTYCZNE 47 (1999) nr 3 (Filologia Klasyczna):

H. Wójtowicz - Recepcja Owidiusza u Seduliusza 77-88; A. Eckmann Pisarze chrześcijańscy wobec kultury klasycznej 89-103.

156. ROCZNIK TEOLOGICZNY 41 (1999) nr 1-2:

J. Przybył - Święty Kolumba. Misjonarz, cudotwórca, opat. W 1400 rocznicę śmierci 95-101; R. Leszczyńska - Filozofia żydowska i Logos Filona z Aleksandrii 103-119.

157. ROCZNIKI TEOLOGICZNE 46 (1999) nr 4-6:

(Nr 4: Historia Kościoła) S. Koczwara - Relacje między Rzymem i Kon- 
stantynopolem w czasie wyboru papieża Hormizdasa (514-523), 119-126; J.R. Marczewski - Papież Leon Wielki jako obrońca Rzymu przed Hunami w świetle świadectw historiograficznych do końca VIII wieku 149-169; J. Pałucki - Paulin z Noli jako asceta i nauczyciel 207-220; M. Szram Interpretacja nieba $i$ ziemi $w$ patrystycznych komentarzach do modlitwy „Ojcze nasz” 231-248; J. Śrutwa - Najstarszy taciński dokument kościelny - analiza treści 281-290; (Nr 5: Teologia Duchowości) J.M. Popławski Chrystocentryzm reguły benedyktyńskiej 137-143; (Nr 6: Teologia Pastoralna) W. Głowa - Święci oraz ich nauczanie w ,homiliach” czytań "Liturgii Godzin» 251-301.

158. SACRA DOCTRINA 44 (1999) nr 1-6:

(Nr 1) G. Cavalcoli - La dimensione escatologica del tempo secondo la rivelazione cristiana 5-46; ( $\mathrm{Nr} 2$ ) A. Carpin - Il sacramento della penitenza nei Concili occidentali dal III al IX secolo 72-145; ( $\mathrm{Nr} 6$ ) G. Bertuzzi Edith Stein e la teologia mistica dello Pseudo-Dionigi 77-86.

159. SACRIS ERUDIRI 38 (1998-1999):

G. Folliet - Dom Eligius Dekkers patrologue 9-14; S. De Smet - De liturgie beschouwd vanuit de tuin van de patristiek 15-35; R. Valandschoot - Dom Eligius Dekkers, een portret even van terzijde 37-45; M. Lamberigts Corpus Christianorum (1947-1955). The laborious journey from dream to reality 47-73; M. Zelzer - Ein Jahrhundert (und mehr) CSEL. Evaluation von Ziel und Veröffentlichungen 75-99; F. Dolbeau - Découvertes récentes d'oeuvres latines inconnues (fin $I I I^{e}$ - début VIII ${ }^{e}$ s.) 101-142; L. Holtz \& D. Poirel - Éditions critiques des oeuvres latines médiévales originaires de la Gaule (IX $X^{e}-X I I^{e}$ sicles) 143-198; L. De Coninck, B. Coppieters \& R. Demeulenaere - Saint Augustin peut-il être l'auteur des sermons «De puero centurionis» et «De filia archisynagogi»? 221-244; G. Folliet - La tradiction indirecte $d u$ «De correptione et gratia» de saint Augustin ( $6^{e}-13^{e}$ s.) 245-280; B. Löfstedt - Textkritisches und Sprachliches $z u$ den neugefundenen Augustinpredigten 281-287; D. Di Mara - De Boethii "Commentariis in Topica Ciceronis" denuo edendis 289-315; A.P. Orbán - Ein anonymer Aratorkommentar in Hs. London, Royal MS. 15 AV-Editio princeps, Teil I, 317-351; M.C. Díaz y Díaz - Isidoriana. II: Sobre unos pseudoisidorianos 353-358; P. Van Deun - Maxime le Confesseur. Etat de la question et bibliographie exhaustive 485-573.

160. SAECULUM CHRISTIANUM 6 (1999) nr 1-2:

(Nr 1) P. Nowogórski - Topografia Jerozolimy wczesnochrześcijańskiej wedtug „Mapy z Madaby” 5-17; S. Kobielus - Zasady estetyki bizantyńskiej sformułowane na podstawie opisów światyń z IV, V, VI i XI wieku, 75-86; (Nr 2) T. Kołosowski - Nauczanie biskupa Cezarego z Arles na temat kultu świętych $w$ kontekście ówczesnej religijności chrześcijańskiej $5-16$. 
161. SALVATORIS MATER 1 (1999) nr 1-4:

(Nr 2) K. Witko - Maryja w zbawczej „ekonomii” Ojca wedtug «Adversus haereses»Ireneusza z Lyonu 179-184; B. Kochaniewicz - Bóg Ojciec i Maryja w tajemnicy podwójnych narodzin Chrystusa wedtug Piotra Chryzologa 185-197; J. Królikowski - Maryja w perspektywie prawdy o Ojcu. Kilka uwag o mariologii Ojców Kapadockich 198-209; S. Kur - Bóg Ojciec a Maryja w tradycji etiopskiej 210-222; J. Woźniak - Bóg Ojciec a Maryja w literaturze syryjskiej 223-231; J.A. Wojtczak - Chrystus jako Syn Dziewicy według Laktancjusza 339-341; W. Kania - Nauka o Maryi św. Jana Chryzostoma w kazaniu na Narodzenie Pańskie 342-346; ( $\mathrm{Nr} 3$ ) M. Zachara - Maryja a Bóg Ojciec w najstarszych rzymskich księgach liturgicznych 13-24; W. Głowa - Bóg Ojciec i Maryja w homiliach Liturgii Godzin 67-80; H. Paprocki - Theotokos w nauce Ojców greckich VII i VIII wieku 231-238.

162. SCIENCE ET ESPRIT 51 (1999) nr 1-3:

J.F. Racine - L'utilisation des Pères en critique textuelle du Nouveau Testament. Promesses et obstacles 161-170.

163. SCRIPTA THEOLOGICA 31 (1999) nr 1-3:

V. Sanz Santacruz - Filosofía y Teología en el «Octavius» de Minuncio Félix 345-365; L.F. Mateo Seco - Salvación y divinización (La leccion de los Padres) 453-469.

164. SCRIPTURA SACRA 3 (1999) nr 3:

K. Bardski - Trzykrotnie zapleciony sznur Eklezjastesa (Koh 4, 12b) i jego symbolika $w$ tradycji Izraela i Kościota 5-44.

165. SCUOLA CATTOLICA 127 (1999) nr 1-6:

A. Elli - Cristianesimo e paganesimo in Egitto (IV-VI secolo) 619-648.

166. SEDES SAPIENTIAE (1999) nr 67-70:

A. Patfoort - Le Filioque, avant le concile d'Éphèse 35-47.

167. STUDENCKI BIULETYN HISTORYCZNY (1999) nr 1-2:

(Nr 1) M. Kędzierski - Życie Atanazego z Aleksandrii 5-11; (Nr 2) M. Kędzierski - Prawdziwe $i$ fatszywe zarzuty przeciwko Atanazemu $z$ Aleksandrii 55-61.

168. STUDIA ANTIQUITATIS CHRISTIANAE 14 (1999):

W. Myszor - Rola kobiet w chrześcijaństwie II i III wieku: wdowy, dziewice $i$ diakonisy 12-19; M. Starowieyski - Od legendy do historii: święte założycielki Kościołów Gruzji i Armenii 20-31; A. Eckmann - Wielkość i godność kobiety wedtug świętego Augustyna 32-42; S. Strękowski - Makryna Młodsza: mistrzyni zycia duchowego wedtug św. Grzegorza z Nyssy 43-52; T. Kołosowski - Lucylla $z$ Kartaginy a geneza schizmy donatystycznej 5363; R. Bulas - Brygida, Ita i Darerka: święte Kościoła celtyckiego 64-77; J. Wojtczak - Niewiasta w «Divinae Institutiones» Laktancjusza 78-82; P. Gruszka - Kommodian o niewiastach 81-82; T. Skibiński - Mniszki i egzegetki: kobieta a Pismo Święte $w$ świetle korespondencji świętego 
Hieronima 83-91; Wybrana bibliografia o kobiecie w starożytności, oprac. J. Salamonowicz-Górska, ks. T. Skibiński, ks. S. Strękowski 92-98.

169. STUDIA GNESNENSIA 13 (1999):

G. Lewandowski - Polemika między Tertulianem a Marcjonem na temat jego nauki o „dwóch Bogach” w świetle "Adversus Marcionem» 205-241; B. Czyżewski - Interpretacja Paschy w ujęciu "Homilii paschalnej» Pseudo-Hipolita 243-264.

170. STUDIA LITURGICA 29 (1999) nr 1-2:

P.J. Leifhart - Christs christened into Christ: Priesthood and Initiation in Augustine and Aquinas 68-83; M.F. Connel - Did Ambrose's Sister become a virgin on December 25 or January 6? The earliest western Evidence for Christmas and Epiphany outside Rome 145-158.

171. STUDIA LOVICENSIA. ŁOWICKIE STUDIA TEOLOGICZNE 1(1999):

J. Krykowski - Pokuta jako postawa życia chrześcijańskiego w nauczaniu Tertuliana i Cypriana z Kartaginy 24-46.

172. STUDIA MONASTICA 41 (1999) nr 1-2:

A. de Vogüé - La prière perpétuelle dans l" "Historia monachorum», la passion de sainte Cécile et la vie de saint Samson 7-9; J. Pauli - Peri Xeniteias: Über das Fremdsein. Die dritte Stufe der Leiter des Johannes Klimakos 35-52; A.A. Navarrete - San Benito y Justiniano I, 53-128; G. Burge - Aktive und kontemplative Weise des Betens im Traktat "De oratione» des Evagrios Pontikos 211-242.

173. STUDIA PARADYSKIE 9 (1999):

Z. Izydorczyk - Dzieje Piotra Apostoła i Szymona 101-140.

174. STUDIA PŁOCKIE 27 (1999):

W. Turek - Odrzucenie darów Ducha Świętego a grzech nieodpuszczalny w ujęciu św. Ireneusza 25-36.

175. STUDIA RELIGIOLOGICA (1999) nr 32 (Kościoły Wschodnie):

W. Myszor - Chrześcijaństwo koptyjskie przed inwazja islamu 11-32;

D. Próchniak - Początki Kościoła armeńskiego 33-47; S. Cinal - Perpetua orthodoxia Maronitów 49-63; L. Nieścior - Mistyczne perspektywy apathei w nauce Ewagriusza z Pontu 65-83; I. Trzcińska - O duszy ludzkiej, czyli niektóre aspekty antropologii $w$ homiliach duchowych Pseudo-Makarego 85-99.

176. STUDIA TEOLOGICZNE BIAŁYSTOK-DROHICZYN-ŁOMŻA 17 (1999):

R. Szmurło - Stan badań nad Szenutem z Atripe 215-227; Polemika z gnostycyzmem w pismach Szenutego z Atripe 351-358.

177. STUDIA THEOLOGICA VARSAVIENSIA 37 (1999) nr 1-2:

(Nr 1) L. Misiarczyk - Uwielbienie Ojca poprzez uwielbienie Syna w J 12, 27-33, 21-40; M. Wojciechowski - „Tajemna Ewangelia Marka” z listu 
Klemensa $z$ Aleksandrii do Teodora 41-51; T. Klibengajtis - Powściagliwość (enkrateia) w "Stromatach» Klemensa z Aleksandrii 53-86; H. Cholewińska - Zagadnienie genezy zła w myśli św. Augustyna 87-113; T. Bartoś - Jedność Boga na tle teorii „całości i części” w komentarzu św. Tomasza $z$ Akwinu do «De divinis nominibus» Pseudo-Dionizego Areopagity 116-131; (Nr 2) Mariusz Wiktoryn: Hymny o Trójcy Świętej - tłum. i oprac. T. Stępień 7-26.

178. STUDIA WŁOCŁAWSKIE 2 (1999):

T. Kaczmarek - Organizacja dzieł charytatywnych Kościoła w Kartaginie pod kierunkiem św. Cypriana 125-131; J. Pałucki - Rola sprawiedliwości w życiu społecznym. Studium patrystyczne 178-190; J. Szymański - Szafarz sakramentu pokuty i pojednania. Rys historyczny 266-277; Z. Wróbel Geneza $i$ zarys problematyki dzieta «De cura pro mortuis gerenda» św. Augustyna 293-301.

179. STUDI ECUMENICI 17 (1999) nr 1-4:

D. Popescu - Il primato del papa nella teologia patristica orientale e occidentale: la sua interpretazione alla luce della cultura contemporanea 145161; G. Laiti - Ricapitolazzione e benedizione in Ireneo di Lione 425-436. 180. STUDIUM 95 (1999) nr 1-6:

E. Cavalcanti - L'imperfezione della storia nel «De civitate Dei» di san Agostino 215-224; C.T. Ferretti - In margine agli antichi riti di ordinazione delle diaconese 225-272.

181. ST. VLADIMIR'S THEOLOGICAL QUARTERLY 43 (1999) nr 1-4:

S. Ashbrook Harvey - Embodiment in Time and Eternity a Syriac Perspective 105-129; A. Golitzin - „A Contemplative and a Liturgist”: Father Georges Florovsky on the "Corpus Dionysiacum»131-161; Ch.A. Metteer - „Mary needs Martha”. The Purposes of manual Labor in Early Egyptian Monasticism 163-207.

182. SUMMARIUM 24-25 (1995/96):

H. Wójtowicz - Seduliusz i jego elegie 115-119; K. Leśniewski - Znaczenie nauki Ojców Kościoła w teologii Georges'a Florowsky'ego 219-230.

183. SUMMARIUM 26-27 (1997/98):

H. Wójtowicz - Grzech pierworodny w twórczości Seduliusza 147-148.

184. TEKA HISTORYKA (1999) nr 13-15:

(Nr 14) R. Głowacki - Święci jeźdźcy i mnisi na skraju egipskiej oazy, czyli polskie wykopaliska w Naglun 19-24.

185. TEOFIL 9 (1999) nr 1 (Liturgia):

J.A. Jungmann - Misteria pogańskie i chrześcijańskie, tłum. P. Napiwodzki 28-37.

186. ӨЕОАОГІА 70 (1999) nr 1-4:

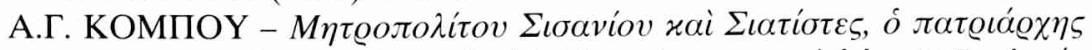

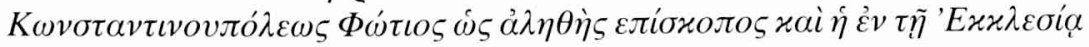




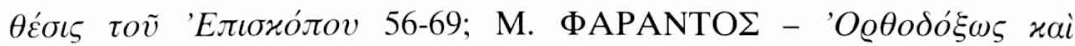

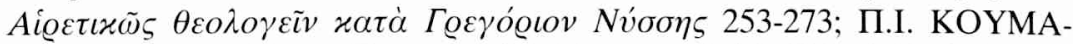

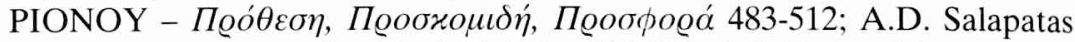
- The Diaconate in Ignatius' Epistles 513-520; J.S. Romanides - Some Soteriological Presuppositions of the Seven Ecumenical Councils 639-645;

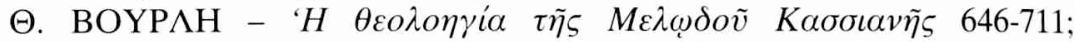
G. Panagopoulos - Die Ikonoklastische Theologie und ihre Christologi-

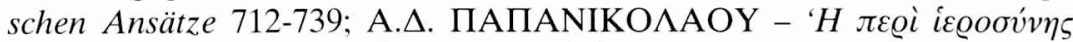

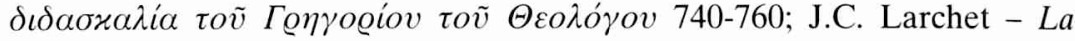
Question du Filioque 761-812; T. Spyros - Spiritual Fatherhood according to St. John Chrysostom's Homilies on Penance in the Light of the Psychology of Depth 826-960.

187. TEOLOGICKÁ REFLEXE (1999) nr 1-2:

A. Prudký - Exegeze starozákonní perikopy a jejé život v křestanské tradici (Iz 44, 1-5), 103-119.

188. TERMINUS 1 (1999) z. 1 :

J. Styka - La culture littéraire romaine dans la Gaule du $V^{e}$ siècle selon le témoignage de Sidoine Apollinaire 43-61; K. Bielawski - Marek Eremita i jego «Prawo Duchowe» 62-71.

189. THEOLOGIE UND PHILOSOPHIE 74 (1999) nr 1-4:

J. Szaif - Selbsterkenntnis: Thomas contra Augustinum 321-337.

190. THEOLOGISCHE QUARTALSCHRIFT 179 (1999) nr 1-4:

H.J. Vogt - De Trinitätstheologie des Papstes Kalixt I, 195-209; Monarchianismus im 2. Jahrhundert 237-259; Seit wann ist die Kirche katholisch? 24-38; H.J. Klauck - Von Kassandra bis zur Gnosis. Im Umfeld der frühchristlichen Glosolalie 289-312.

191. THEOLOGISCHE ZEITSCHRIFT 55 (1999) nr 1-4:

$\mathrm{R}$. Brändle - , Gott wird nicht allein durch richtige Dogmen, sondern auch durch einen guten Lebenswandel verherrlicht”. Zur Verhältnisbestimmung von Glaube und Werken bei Johannes Chryzostomus 121-136.

192. THEOLOGY DIGEST 46 (1999) nr 1-4:

A. Patfoort - The Filioque before the Council of Ephesus 3-9; L.T. Johnson - Koinonia: diversity and unity in early Christianity 303-313; G.B. Ferngren - Medicine and compassion in early Christianity 315-326.

193. THEOTOKOS 7 (1999) nr 1-2:

P. Zannini - Romano il Melode e le tematiche patristiche grecosiriache su $G v$ 2, 1-11, 41-65; G. Ferraro - Interpretazioni patristiche di Gv 2, 4, 214236; G. Gharib - Maria presso la croce nella liturgia bizantina 387-416; P. Sorci - Maria presso la croce nella liturgia romana 417-448.

194. THE THOMIST 63 (1999) nr 1-4:

L.J. Donohoo - The Nature and Grace of «Sacra Doctrina» in St. Thomas's «Super Boetium de Trinitate» 343-401. 
195. TOPOS 7 (1999) nr 5-6 (48-49):

J. Salij - Biblia świętego Augustyna 17-22; A. Siemianowski - Św. Augustyn oraz jego obecność $i$ znaczenie $w$ kulturze europejskiej 27-36; H. Oleschko - Angelologia augustyńska 39-52; K. Koehler - Święty Augustyn i retoryka czyli „Wyznania neofity” 59-66; P.W. Lorkowski - Lekcje Augustyna 71-79.

196. TRIERER THEOLOGISCHE ZEITSCHRIFT 21 (1999) nr 1-4:

B.Studer - Anstöße zu einer neuen Trinitätslehre bei Augustinus von Hippo 123-138.

197. UNIVERSITAS GEDANENSIS 11 (1999) nr 1-2:

J. Majewski - Pathos tou Theou, czyli o ,cierpieniu” Niecierpiętliwego 51-76.

198. VERBO SPEIRO 38 (1999) nr 371-380:

Á. D’Ors - Dos tópicos gnósticos sobre el ser humano: tricotomía y androginia $803-814$.

199. VERITAS 44 (1999) nr 1-4:

J. Lupi - O Homem eo mundo na antropologia teológica de Orígenes 505-514; E. Reinhardt - La condición del ser humano, según la Summa Sententiarum 523-532; S. Magnavacca - Contemplación de lo natural y acción humana en la magia. San Agustín y Picco della Mirandola 831-842.

200. VETERA CHRISTIANORUM 36 (1999) nr 1-2:

(Nr 1) A. Quacquarelli - Le nozze eterne in Giovanni Crisostomo 5-14;

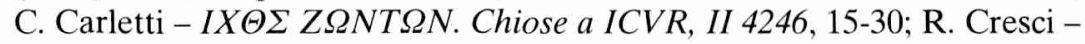
Una Priamel di Gregorio di Nazianzo in Giovanni Geometra 31-37; R. Infante - Gesù, la samaritana e la Samaria (Gv 4), 39-59; M. Marin Ilario, Ambrogio e i passeri de Mateo 61-70; M. Simonetti - Origene e le parabole del regno 109-122; A.F. Felle, G. Disantarosa - Un'iscrizione funeraria cristiana di Roma ritrovata a Palo del Colle (BA): all'origine del culto di s. Damaride 123-136; (Nr 2) C. Kraus Reggiani - La figura di Giobbe in tre documenti del giudaismo ellenistico 165-192; P. Maraval Les premiers developpements du culte des XL martyrs de Sebastée dans l'Orient byzantin et en Occident 193-209; D. Nuzzo - Egiziani a Roma in età tardoantica. Osservazioni sulle fonti epigrafiche e letterarie 211-238; G. Otranto - Il pellegrinaggio nel cristianesimo antico 239-257; A.M. Ramelli - L'apologia siriaca di Melitone ad „Antonino Cesare”: osservazioni e traduzione 259-286; S. Santelia - Note a Sidonio Apollinare Carm. 24, 16-19 (sul culto di san Giuliano di Brioude 287-296; R. Giuliani - Gli arredi musivi e plastici del complesso paleocristiano di Barletta 297-322; F.M. Catarinella Due citazioni non identificate nell'epistola 23 di Paolino da Nola 323-328.

201. VIA CONSECRATA 2 (1999) nr 1-12:

(Nr 1) Jan Paweł II - Reguła św. Benedykta programem życia również na dzisiaj. Przemówienie na III Międzynarodowym Sympozjum Przełożonych Wspólnot Sióstr Benedyktynek (11 IX 1998 r.), 4-5. 
202. VIGILIAE CHRISTIANAE 53 (1999) nr 1-4:

R.E. Aldridge - The Lost Ending of the "Didache» 1-15; M.D. Goulder Ignatius' „Docetists” 16-30; R. Hanig - Tatian und Justin. Ein Vergleich 31-73; E.P. Meijering - Bemerkungen zum Nachleben des Irenäus im Streit der Konfessionen 74-99; D.T. Runia - Philo of Alexandria and the Greek Hairesis-Model 117-147; G.E. Sterling - „The School of Sacred Laws”: The Social Setting of Philo's Treatises 148-164; D.D. Hannah - The Ascension of Isaiah and Docetic Christology 165-196; N.L.A. Tidwell - «Didache» XVI 1

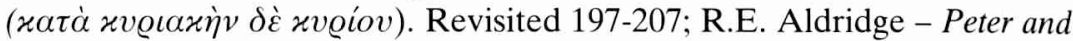
the „Two Ways” 233-264; W. Mayer - Constantinopolitan Woman in Chrysostom's Circle 265-288; M.D. Nispel - Christian Deification and the Early „Testimonia” 289-304; J. Fossum - The Myth of the Eternal Rebirth. Critical Notes on G.W. Bowersock, "Hellenism in Late Antiquity» 305-315; M. Illert - Zum „Descensus ad infernos” bei Makarios 321-322; E. Lucchesi - Trois éloges coptes de Jean-Baptiste attribués à Athanase, Théophile et Cyrille d'Alexandrie 323-324; K. Berding - Polycarp of Smyrna's View of the Authorship of 1 and 2 Timothy 349-360; P. Schüngel - Gnostische Gotteslehren. Zum 7. und 8. Fragment des Basilides, zu Valentins 5. Fragment und zwei antiken Kommentaren zu diesem Fragment 361-394; M. Heath - Echoes of Longinus in Gregory of Nyssa 395-400; W. Fauth Der christliche Reiterheilige des Sisinnios-Typs im Kampf gegen eine vielnamige Dämonin 401-425.

203. VITA MONASTICA 53 (1999) nr 210-212:

(Nr 210) V. Bonato - Ancora su eros e agape 41-48; (Nr 212) M.I. Danielli - Il cammino d'Israele nel deserto nella lettura di Origene 5-31.

204. VIVENS HOMO 10 (1999) nr 1-2:

M. Naldini - Lo Spirito Santo come ,forma” dell'uomo (Basilio Magno "De Spiritu Sancto» 26, 61). Nota esegetica 329-336.

205. VOX LATINA 35 (1999) nr 135-138:

A. Augustinus - Homilia natalicia 470-472.

206. THE WESTMINSTER THEOLOGICAL JOURNAL 61 (1999) nr 1-2: R. Letham - „In the Space of Six Days”: The Days of Creation from Origen to the Westminster Assembly 149-175.

207. ВОПРОСЫ ФИЛОСОФИИ (1999) nr 1-12:

(Nr 1) А.В. Апполонов - „Вьедение в камегорические силлогизмь” А.М.Т.С. Боэция 136-144; А.М.Т.С. Боэций - Вьедение в камегорические силлогизмы 145-171.

208. WORSHIP 73 (1999) nr 1-6:

D. Shin - Some Light from Origen 399-425; M.E. Johnson - The Baptismal Rite and Anaphore in the Prayers of Serapion of Thmuis: An Assessment of a Recent „Judicious Reassessment” 140-168.

209. WORT UND DIENST (1999) nr 25: 
D.V. Du Toit - Die Vorstellung eines Begleitdämons in Philostrats «Vita Apolonii» 149-166.

210. WROCŁAWSKI PRZEGLĄD TEOLOGICZNY 7 (1999) nr 1-2:

(Nr 1) R. Groń - Fenomen Doktora Kościoła w historycznym rozwoju 53-64.

211. ZEITSCHRIFT FÜR ANTIKES CHRISTENTUM 3 (1999) nr 1-2:

K.H. Uthemann - Ein zweiter Bericht über griechische Editionen, Handschriften und Hilfsmittel 3-49; H.J. Vogt - Bemerkungen zur Echtheit der Ignatiusbriefe 50-63; Das Glaubensbekenntnis des Johannes Chrysostomus? Versuch einer „Symbolstudie” mit einem Exkurs zu Baruch 3, 38 bei den Vätern 64-86; J. Ulrich - Wallfahrt und Wallfahrtskritik bei Gregor von Nyssa 87-96; H. Tränkle - Der Brunnen im Atrium der Petersbasilika und der Zeitpunkt von Prudentius' Romaufenhalt 97-112; J. Van BanningBemerkungen zur Apringius von Beja-Forschung 113-122; M. Wallraff Patristische Arbeitshilfen im Internet (II). Zeitschriften und Reihen 120122; R.W. Mathisen - A New Fragment of Augustine's "De nuptiis et concupiscentia» from the Codex Sangallensis 190, 165-183; H.G. Bethge, U.U. Müller, U.K. Plisch - Bericht über Editionen von koptischen Texten und Publikationen von Hilfsmitteln 184-201; D. Wanke - Irenäus und die Häretiker in Rom. Thesen zur geschichtlichen Situation von "Adversus haereses» 202-240; R. Hanig - Der Beitrag der Philumene zur Theologie der Appeleianer 241-277; G.Ch. Hansen - Mutmaßungen über die Kirchengeschichte des Sokrates 278-285.

212. ZEITSCHRIFT FÜR KATHOLISCHE THEOLOGIE 121 (1999) nr 1-4: L. Lies - Origenes und Reinkarnation (Teil 1) 139-158; Origenes und Reinkarnation (Schluß) 249-268; D. Winkler - Theodosius II von Alexandrien (533-566). Ökumenischer Patriarch der Miaphysiten 396-412.

213. ZEITSCHRIFT FÜR THEOLOGIE UND KIRCHE 96 (1999) nr 1-4:

A.M. Schwemer - Prophet, Zeuge und Märtyrer. Zur Entstehung des Märtyrerbegriffs im frühesten Christentum 320-350.

214. ZNAK 51 (1999) nr 524-535:

(Nr 529) M. Borkowska - Wykrzyknik, czyli cuda w tradycji Ojców Pustyni 39-44; (Nr 532) M. Borkowska - Sylwetki Ojców Pustyni (1). Arseniusz 124-129; (Nr 534) M. Borkowska - Sylwetki Ojców Pustyni. Mojżesz 118-121.

215. ŻYCIE DUCHOWE 6 (1999) nr 20:

(Nr 20) D. Kowalczyk - Dlaczego święty Augustyn nigdy się nie spowiadat? 70-79; M. Dzielska - Świetlista ciemność 116-131. 